Grand Valley State University

ScholarWorks@GVSU

\title{
Promoting Social Interactions Between Students with Autism Spectrum Disorders and Their Peers in Inclusive School Settings
}

Jamie S. Owen-DeSchryver

Grand Valley State University

Edward G. Carr

State University of New York at Stony Brook

Sanja I. Cale

Long Island University

Audrey Blakeley-Smith

University of Colorado at Denver and Health Sciences Center

Follow this and additional works at: https://scholarworks.gvsu.edu/psy_articles

Part of the Psychology Commons

\section{ScholarWorks Citation}

Owen-DeSchryver, Jamie S.; Carr, Edward G.; Cale, Sanja I.; and Blakeley-Smith, Audrey, "Promoting Social Interactions Between Students with Autism Spectrum Disorders and Their Peers in Inclusive School Settings" (2008). Peer Reviewed Articles. 18.

https://scholarworks.gvsu.edu/psy_articles/18

This Article is brought to you for free and open access by the Psychology Department at ScholarWorks@GVSU. It has been accepted for inclusion in Peer Reviewed Articles by an authorized administrator of ScholarWorks@GVSU.

For more information, please contact scholarworks@gvsu.edu. 


\title{
Promoting Social Interactions Between Students With Autism Spectrum Disorders and Their Peers in Inclusive School Settings
}

\author{
Jamie S. Owen-DeSchryver \\ Grand Valley State University, Allendale, Michigan \\ Edward G. Carr \\ State University of New York at Stony Brook \\ Sanja I. Cale \\ Long Island University and The Institute for Children With Autism, Long Island, New York \\ Audrey Blakeley-Smith \\ University of Colorado at Denver and Health Sciences Center
}

\begin{abstract}
This study evaluated the impact of a peer training intervention on social interactions among three students with autism spectrum disorders (ASD) and their typical peers. Two second graders and one fourth grader with ASD participated. For each student with ASD, two to four typical peers participated in training sessions that targeted increased social interactions. Data collected during lunchtime and recess showed that the peer training intervention generally resulted in increased initiations by trained peers as well as increased initiations and responses by students with ASD. Unexpectedly, untrained peers also showed increased initiations. Future research directions are discussed, including characteristics of the peers selected for training (e.g., gender, popularity) and measurement of qualitative changes in social relationships and opportunities.
\end{abstract}

Keywords: autism; social skills; peer training; social initiations; schools

A utism spectrum disorders (ASD), including autism, Asperger syndrome, and pervasive developmental disorder-not otherwise specified, are a group of disorders characterized by impairments in social interaction, deficits in communication, and restricted and repetitive patterns of behavior (American Psychiatric Association, 2000). In Kanner's (1943) description, deficits in affective contact were considered to be central to the autism diagnosis. More recently, Laushey and Heflin (2000) suggested that core impairments in social behavior should be viewed as the defining feature of ASD. While the social difficulties displayed by individuals with ASD vary from individual to individual, these difficulties may include impaired eye gaze, poor joint attention, few verbal initiations, and failure to develop age-appropriate friendships (Dawson et al., 2004). Additionally, individuals with ASD often have difficulty generalizing learned skills to new settings or using newly acquired skills in the presence of novel people or materials (Handleman, 1999). Consequently, the National Research Council (2001) recommended that students with ASD be taught skills in the natural contexts in which they would be used. These issues, coupled with the legal mandates of the Individuals with Disabilities Education Improvement Act of 2004, have led to the placement of more students with ASD in general education classrooms in public schools. This outcome has resulted in an increasing emphasis on developing methods to meet the needs of students with ASD as they participate in these inclusive school environments.

Initially, it was assumed that the placement of students with ASD in regular education settings would result in social benefits for these students. However, findings in this area have been mixed (Harrower \& Dunlap, 2001). In some cases, limited or qualitatively poor social interactions have been reported in inclusive environments. In

\footnotetext{
Authors' Note: The authors would like to thank Mike Darcy at the Autism Help Center and Gail McGee at the Emory Autism Center for their assistance in the completion of this study and the subsequent manuscript. This article is based on a doctoral dissertation submitted by the senior author to the Department of Psychology at the State University of New York at Stony Brook.
} 
one study conducted with students with special needs, Hilton and Liberty (1992) reported that $78 \%$ of interactions were purely instructional in nature and occurred between the students with special needs and their teachers, teaching assistants, or peer tutors rather than with classmates who were not acting as tutors. Fewer than $5 \%$ of student contacts were related to companionship or social or friendship activities with the students' typical peers. Furthermore, due to their particular deficits, students with ASD may not participate in play activities with other students even when they are in close proximity to their typical peers. Anderson, Moore, Godfrey, and Fletcher-Flinn (2004) conducted observations of 10 children with autism during recess periods in their mainstream kindergarten and elementary school placements. The children with autism were observed to engage primarily in solitary play activities even when they were with their peers in active and crowded places. Similarly, Kamps et al. (2002) showed that students with autism engaged in fewer reciprocal interactions and interactions with shorter durations with untrained than with trained peers, even if the untrained peers were familiar to the children with autism. These studies suggest that placement in inclusive settings is not sufficient to encourage authentic social interactions between students with ASD and their typical peers.

Research has demonstrated the effectiveness of different strategies for facilitating relationships and social interactions in elementary-age students with ASD. Rogers (2000) reviewed this literature and identified several effective techniques, including Social Stories ${ }^{\mathrm{TM}}$, social skills groups, peer tutoring, pivotal response training, visual cueing in the form of scripts, and adultdirected instruction. The development of peer networks (Garrison-Harrell \& Kamps, 1997; Kamps et al., 1997) and general peer training interventions (Gonzalez-Lopez \& Kamps, 1997; Kohler et al., 1995; Lee \& Odom, 1996; McGee, Almeida, Sulzer-Azaroff, \& Feldman, 1992; Morrison, Kamps, Garcia, \& Parker, 2001) have also been identified as valuable strategies that can support positive social outcomes. Rogers (2000) further noted that the field is shifting emphasis from adult-directed to peer-based instructional strategies, including peer training, peer tutoring, and peer networking. These approaches, which may be collectively referred to as peer-mediated interventions, focus on using typical classmates to improve the behaviors of students with ASD (Kamps et al., 1998). Peer-mediated strategies have been found to be effective in increasing social initiations that peers direct toward students with special needs, such as sharing, suggesting play ideas, assisting, and being affectionate (Kohler et al., 1995; Lee \& Odom, 1996). Other research has demonstrated quantitative changes in social interactions between students with autism and their peers when peers are trained to make requests and comments to their peers with autism (Morrison et al., 2001); to prompt students with autism to verbally request items and engage in turntaking (McGee et al., 1992); and to prompt students with autism to imitate actions and follow simple instructions (Gonzalez-Lopez \& Kamps, 1997).

Taken collectively, these studies indicate that peer training is a viable strategy for increasing interactions between typical peers and students with ASD. However, only a few of these studies assessed changes in social behaviors that occurred during naturalistic free-play activities. Morrison et al. (2001) noted that some generalization of social interaction occurred in lunch and recess probes among half of their participants, and McGee et al. (1992) reported that social interactions successfully generalized to free-play activities for one of their three participants. These results indicate the need for further research to evaluate the use of peer-mediated strategies in naturalistic school activities and settings as well as to determine the factors that contribute to the success, or lack thereof, of these interventions.

A significant portion of the existing research on interventions to improve the social functioning of students with ASD focuses on students in preschool or kindergarten settings (Kohler et al., 1995; Laushey \& Heflin, 2000; McGrath, Bosch, Sullivan, \& Fuqua, 2003). As Pollard (1998) proposed, this emphasis may occur because parents and teachers report concerns about social development during this time, as opposed to during later years, when academic development becomes the primary focus. In addition, researchers may concentrate on younger students because children at this age are more likely to be involved in social activities in the educational setting, whereas older students consistently receive more academically focused programming. The present study, like a few recent investigations (Kamps et al., 2002; Morrison et al., 2001), focused on elementary school-age students in public schools.

In one early study demonstrating the importance of evaluating social interactions in integrated settings, Strain (1983) showed that students with autism engaged in higher rates of social interaction when they participated in an integrated recess period than when they participated in a recess period with other students with special needs. While these findings differ somewhat from results cited by Anderson et al. (2004), they do suggest the potential impact of contextual variables on social exchanges. Additional research by Nabors, Willoughby, Leff, and McMenamin (2001) supports the importance of using playground time to build social interactions. Surprisingly, however, few recent studies have evaluated social interactions in naturalistic elementary school settings. To ensure that the context for the studied interactions was ecologically valid, 
the present study focused on social interactions that occurred during lunchtime and recess with students with ASD who were placed in inclusive settings.

\section{Method}

\section{Participants With ASD}

Two students diagnosed with autism and one student diagnosed with Asperger syndrome participated in the study. All participants had been diagnosed by independent psychiatrists or psychologists and attended public schools in suburban Long Island, New York. These students were identified through contact with consultants from an agency that provides educational and behavioral support to students with ASD. The first three students who were recommended for the study, and for whom parent permission was obtained, were included. Although the three students functioned at different academic levels, all showed significant social difficulties, as reflected in consultant, parent, and teacher reports. In order to ensure confidentiality, all participant names have been changed.

John, a 7-year-old boy diagnosed with autism, was placed in a general education second-grade class, where he received the support of a full-time aide. John's full-scale IQ score on the Wechsler Intelligence Scale for Children-Third Edition (WISC-III; Wechsler, 1991) was 76. He received individual speech therapy and occupational therapy services, but all other instruction occurred with his regular classmates. John exhibited limited social interactions. He generally spoke only to adults during lunchtime and played by himself on the playground while repeating cartoon phrases. John showed several behaviors that interfered with social activities, such as verbal perseveration and stereotypic behavior (e.g., shaking his head, shaking his fingers, jerking body movements). He also displayed some verbally and physically aggressive behaviors (pushing, kicking, and swearing) toward adults and peers.

David, a 10-year-old boy diagnosed with Asperger syndrome, was in a fourth-grade class. His full-scale IQ on the WISC-III was 97. He received individual speech therapy services and resource room services that focused primarily on organizational, writing, and study skills but remained with his typical classmates for academic instruction (e.g., reading, math, science) and other school activities. David engaged in only limited social interactions. During lunch, he ate alone in the cafeteria, rarely interacting with other students. He often finished his lunch quickly and put his head down on the table. Throughout the entire recess period, David consistently remained alone on the playground swing and only spoke to other children if they initiated an interaction.
George, a 7-year-old boy diagnosed with autism, was placed in a second-grade inclusion classroom, where he received instruction with 15 typical peers and 3 peers with other disabilities. George received special services, including speech therapy, occupational therapy, physical therapy, and adapted physical education. He also shared an aide with one other student and received instruction from a special education teacher within the general education classroom. At his parents' request, George's IQ was not divulged for the purposes of this investigation; however, classroom observations of George suggested that his academic performance was significantly below secondgrade level (i.e., his academic work and performance expectations were modified). George showed limited baseline levels of social interaction. During recess activities, he often followed peers without speaking to them or actively participating in any of the group games. During lunch, the majority of his interactions were with adults. George was also observed to display negative verbalizations, including calling other students "losers" or telling them to "shut up," and negative or socially inappropriate behaviors, including taking toys or materials from other students, finger-flapping, and perseverative verbalizations.

Throughout the course of the study, researchers did not work directly with the students with ASD, nor did they describe the nature of the research project to the participants with ASD, although it is possible that the participants may have indirectly received this information from parents or peers. None of the participants were involved in any other interventions directly targeting social skills during the study. Indirect social skills instruction may have occurred throughout the school day, because the participants were supported by school staff who provided prompting and feedback in these areas to meet the goals set forth in student Individualized Education Programs. For the purposes of the study, school staff members were neither encouraged to provide nor asked to avoid social skills instruction. Two of the participants, David and George, had participated in social skills groups in prior school years. Due to the significance of his behavioral problems, John met informally with the school guidance counselor during the period of the study. Although these sessions occasionally involved discussion of social issues, the primary goal of these meetings was the development of behavioral self-management strategies, such as relaxation and use of appropriate modes of communication when requesting breaks.

\section{Peers}

Typical peers were selected to participate in the peer training intervention based on researcher observations in the classroom and recommendations from classroom 
teachers and classroom assistants. After a number of potential peers were suggested, the general education classroom teachers were allowed to choose the peers who would be contacted about involvement. Peers were selected based on the following criteria (described by McEvoy, Shores, Wehby, Johnson, \& Fox, 1990): (a) student willingness to participate; (b) satisfactory attendance record in school; (c) overall compliance with instruction; and (d) student ability to make up any schoolwork missed during training. Before training was initiated, permission was obtained from the parents of the selected peers. Four typical peers from John's second-grade classroom (two boys and two girls) and three typical peers from David's fourth-grade classroom (one boy and two girls) participated in the peer training intervention. Two sets of peers from George's secondgrade classroom participated in the intervention: The initial set of peers consisted of only two students, both boys, because of difficulties in obtaining permission from the parents of the third selected peer. After it was determined that the training with these two peers was not succeeding in increasing peer interactions, a second set of three peers, all girls, was selected for participation.

\section{Procedure}

The study was conducted across the span of approximately 6 months. For each student with ASD, baseline data collection occurred for 3 to 6 weeks (baseline phase), followed by approximately two weeks during which the peer training intervention occurred. After completion of peer training, data were again collected during lunchtime and recess for up to 14 weeks to determine the effects of the intervention (post intervention phase).

\section{Baseline}

Baseline data were collected during lunchtime and recess because these two activities provided consistent opportunities for students to participate in social interactions, whereas other classroom activities either did not regularly encourage social interactions or generally discouraged such interactions. During baseline, researchers observed and recorded social interactions (described in detail later) between the students with ASD and their schoolmates throughout the lunch and recess periods. Observations were conducted at random approximately 1 or 2 days per week. Depending on school and student schedules, lunch observations typically lasted for 10 to $15 \mathrm{~min}$, and recess observations generally lasted for 15 to $20 \mathrm{~min}$. When making observations, researchers remained as far from the students with ASD as possible (generally 3-6 m) while still ensuring that they could hear any verbal interactions. If the observers were questioned by any of the students, including peer training participants, regarding their presence at the school, they replied that they were there to observe how students talked and played during lunch and recess.

\section{Peer Training Intervention}

After baseline data collection was completed, peers were taken in groups to separate locations in the schools, and training was completed by the first or fourth author. Training occurred in three sessions ranging from 30 to $45 \mathrm{~min}$ in length. To minimize disruptions to student and teacher schedules, students were removed from classroom activities only at times permitted by the classroom teachers. Some students participated in training during lunchtime and recess, while others were trained during nonacademic activities or free periods in the classroom schedule. Upon completing each training session, the second-grade students were allowed to choose a sticker. The fourth-grade students did not receive any tangible reward but were thanked for their participation. Upon completion of the study, all participating peers received a \$10.00 gift certificate to a neighborhood toy store. Students were unaware that this gift certificate would be provided before they received it. Data collection did not occur during the 2 weeks that the peer training intervention was conducted.

Phase 1. In the first phase of training, students were provided with a rationale for developing friendships with students with disabilities. The format of this training varied depending upon the age of the participating students. For the second-grade students, training consisted of reading and discussing a children's book about a boy with autism who was in an inclusion classroom (OwenDeSchryver, 2002). This book describes the characteristics of the child with autism as seen from a classmate's perspective. The story notes that the boy often repeats cartoon phrases and spins in circles instead of engaging other children on the playground. It also describes strategies that the classmate uses to befriend the student with autism. For the fourth-grade peers, training consisted of a modified circle-of-friends activity similar to the friendship awareness activity described by Fritz (1990). During this activity, students were guided to fill in names in four concentric circles on a chart, where each of the rings stood for a different level of relationship: loved ones and family members (e.g., parents, siblings) in the innermost ring, then close friends (e.g., best friends), then acquaintances (e.g., other friends from school), and finally people paid to be with the student 
(e.g., teachers, coaches) in the outermost ring. This activity was used to illustrate how important it is for students with special needs to experience peer friendships rather than only relationships with paid adults.

Phase 2. During Phase 2 of training, each group of students was led in a general discussion about the strengths and preferences of the classmate with ASD. Questions such as "What is John good at?" and "What does David like to do?" were posed. The purpose of this phase was to help students recognize that all children, both children with and without disabilities, have special abilities and areas of need. To illustrate this point further, peers were asked to discuss their own strengths and weaknesses. Weaknesses were discussed in terms of "things you're still learning to do" (e.g., playing the piano, spelling difficult words) and "things [the classmate with ASD] is still learning to do" (e.g., talking to other students, playing games on the playground, sitting in his seat during math class).

Phase 3. In the final phase of peer training, peers were involved in a guided discussion relating to five central themes, which were expressed as questions:

1. "When can you play with and talk to [student name] at school?" (e.g., recess, lunchtime, group work, computers)

2. "What are some topics you can talk about with [student name]?" (e.g., karate, movies, dinosaurs, school, animals, cartoons)

3. "What are some activities that you can do with [student name] during recess?" (e.g., tag, hide-andseek, kickball, soccer, climbing, running races)

4. "How can you help [student name] learn to play?" (e.g., invite him to play the games with you, teach him the rules of the games, let him try more than one time, take turns with him)

5. "What can you do if [student name] doesn't respond or shows unusual behavior?" (e.g., ask him questions again, move nearer to him, ask whether he wants to do something else, talk about something different, go near him and don't leave him alone, remind him of other things)

The purpose of this phase was to provide concrete information and strategies that would help peers during their interactions with the students with ASD. The facilitator asked peers each of the above questions and then guided the students to discuss appropriate responses. Whenever necessary, answers were prompted by the facilitator. Students were also provided with a series of worksheets on which the questions were typed, with space left beneath each question. To provide students with visual reminders of the strategies discussed, peers were guided to write or draw pictures of possible answers to the above questions on these worksheets and combine them to create a "friendship book." When the training sessions were completed, peers were allowed to keep the books they had made for future review.

As during the baseline phase, researchers observed and recorded social interactions between the students with ASD and their schoolmates throughout the lunch and recess periods. Observations were again conducted at random approximately 1 or 2 days per week.

\section{Response Recording and Reliability}

\section{Target Measures}

All observations were conducted by graduate students in clinical psychology who had extensive experience working with students with ASD in inclusive school placements. Observations occurred randomly, approximately once or twice per week, during lunchtime and recess. The duration of the lunch and recess periods was also recorded because these times often varied slightly from day to day, depending upon school schedules. For all target measures, data were collected using a frequency recording system.

For the trained peers, data were collected on (a) the number of social initiations directed toward the students with ASD and (b) the number of responses by the trained peers to initiations made by the students with ASD. Data for trained peer initiations were pooled, reflecting the total number of initiations directed toward the student with ASD by the group of 2 to 4 typical peers who would be participating in the peer training (baseline phase) or who had participated in the peer training (post intervention phase). Data for trained peer responses were similarly pooled for the entire group of 2 to 4 peer training participants. Observers combined data in this manner with one exception. For George, baseline ratings for initiations and responses were not separately recorded for the three peers who later constituted trained peer Group 2 (i.e., their data were combined with data for all other untrained peers). For the untrained peers, data were collected on (a) the number of social initiations directed toward the students with ASD and (b) the number of responses by the untrained peers to initiations made by the students with ASD. These data were collected for the entire set of untrained peers, and therefore included data from 20 to 50 typical peers who did not participate in the peer training intervention but who did participate in lunch and recess in the same period as the student with ASD. The number of 
students varied greatly depending on the school and the number of same-grade classrooms slotted to participate in lunch and recess simultaneously. For each student with ASD, data were collected on (a) the number of social initiations directed toward peers and (b) the number of responses to social initiations made by his peers. Rates were then calculated for each of the target behaviors by dividing the number of occurrences of the target behavior during lunch and recess periods by the duration in minutes of the lunch and recess periods.

\section{Social Initiations}

Social initiations were defined as positive social behaviors that began an interaction with another student (Davis, Langone, \& Malone, 1996). Examples of behaviors that were scored as social initiations included handing a toy to another child; asking if the child wished to join an activity; offering assistance during play; greeting, questioning or praising the child; or commenting on the child's activity.

\section{Responses to Social Initiations}

Responses to social initiations were defined as positive social behaviors made toward a child that were preceded by a positive social initiation from that child (Davis et al., 1996) or by a response from that child. Examples of responses to social initiations included complying with another student's request, replying to a verbal interaction, or looking at a child in response to hearing him or her call one's name. Where a conversation occurred between a student with ASD and a peer, each consecutive verbalization after the first initiation was scored as a response. For example, if a peer asked the student with ASD whether the student with ASD wanted to play tag, this question was scored as an initiation. If the student responded, "Tag after lunch?" this remark was scored as a response. If the peer then answered, "Yes, over by the swing set," this statement was also recorded as a response. A behavior was recorded as a response only if it occurred within $10 \mathrm{~s}$ of a child's initiation or response.

\section{Reliability}

Reliability data were collected by an independent observer for $36 \%$ of sessions across the baseline and intervention phases (22\% of sessions during baseline and $44 \%$ during intervention). Mean interobserver agreement was calculated for each of the target behaviors by dividing the frequency of the target behavior recorded by Observer 1 by the frequency of the target behavior recorded by Observer 2 and multiplying the result by 100 . Across baseline and intervention phases, mean percentage agreement was $81 \%$ for initiations by trained peers, $83 \%$ for initiations by untrained peers, and $83 \%$ for initiations by the students with ASD. Mean percentage agreement was $87 \%$ for responses by trained peers, $83 \%$ for responses by untrained peers, and $81 \%$ for responses by the students with ASD.

\section{Design}

Following standard research practice in the field, a multiple baseline design across the three participants with ASD was used to evaluate the efficacy of the peer training intervention (Kazdin, 1982; Tawney \& Gast, 1984). Consistent with the logic of the multiple baseline design, the intervention was implemented for each participant following demonstration of low, stable baseline rates of peer initiations toward the students with ASD. Thus, the intervention occurred after varying baseline lengths: 4 sessions for John, 6 for David, and 8 for George.

\section{Results}

\section{Peer Initiations Toward Students With ASD}

Figure 1 presents data on the rate of peer initiations toward the students with ASD. Peer initiations increased for all three participants following peer training. For John, trained peer initiations increased from an average of 0.06 per minute in baseline to 0.23 initiations per minute following intervention. For David, trained peers showed no initiations during baseline and averaged 0.25 per minute in the postintervention phase. Finally, for George, trained peers averaged 0.01 initiations per minute in baseline. Group 1 of trained peers averaged 0.10 initiations per minute following intervention, with a decreasing trend, and Group 2 of trained peers averaged 0.29 initiations per minute, with the last four sessions averaging 0.08 initiations per minute.

Figure 1 also presents the data for untrained peers. Even though the intervention did not target untrained peers, these peers also showed increased initiations toward the three participants with ASD during the post intervention phase. Untrained peers directed an average of 0.18 initiations per minute toward John during baseline and 0.57 per minute following intervention. For David, untrained peers averaged 0.04 initiations per minute during baseline and 0.26 per minute during the postintervention phase. For George, untrained peers averaged 0.13 initiations per minute during baseline, 0.08 initiations per minute during the first phase of the peer training intervention (Group 1), and 0.32 initiations per minute during the second phase of the peer training intervention (Group 2).

Table 1 shows the number of social initiations and average initiations per session (i.e., during lunchtime and 
Figure 1

Peer Initiations per Minute Toward the Students With Autism Spectrum Disorders

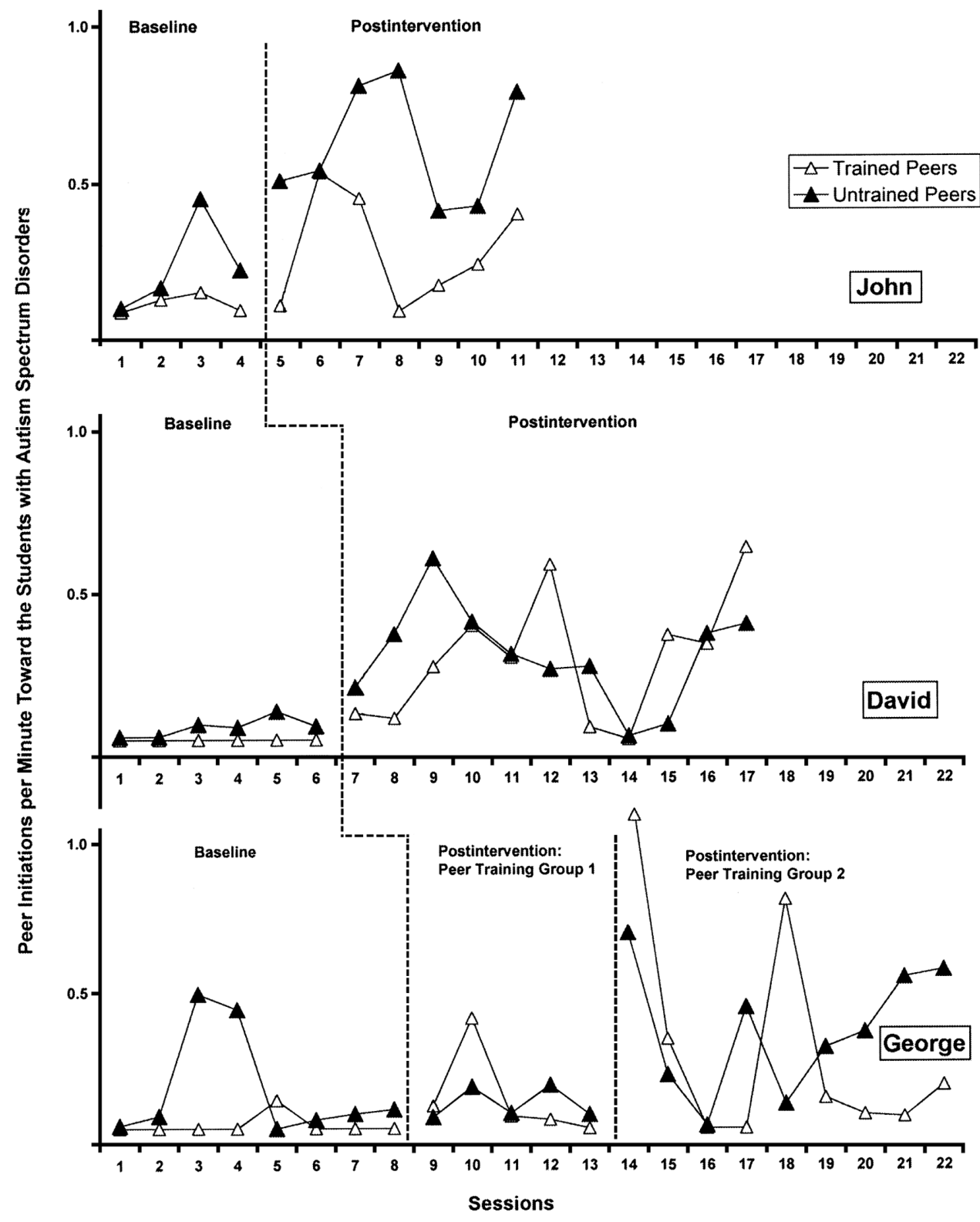

recess) directed toward the students with ASD. These data are aggregated for both trained and untrained peers, contrasting with Figure 1 where social initiations are depicted separately for trained and untrained peers. For all participants, there were substantial increases in peer initiations following intervention. For example, whereas peers made only 22 initiations to John in baseline, they made 143 initiations to him following intervention. As is shown, similar dramatic increases in the number of initiations directed toward both David and George were noted.

\section{Responses by Students With ASD to Peer Initiations}

Figure 2 depicts the rate of responses by students with ASD to peer initiations. Data were not recorded separately for responses to initiations by trained peers versus those to initiations by untrained peers. As shown, responses typically increased for the three participants following intervention. John averaged 0.13 responses per minute in baseline and 0.45 per minute following 
Table 1

Number of Combined Peer Initiations (Trained and Untrained Peers) Toward Students With ASD Across Baseline and Intervention Phases

\begin{tabular}{lccc}
\hline Participant/Condition & $\begin{array}{c}\text { Frequency of } \\
\text { Peer Initiations }\end{array}$ & $\begin{array}{c}\text { Number of } \\
\text { Sessions }\end{array}$ & $\begin{array}{c}\text { Average Initiations } \\
\text { per Session }\end{array}$ \\
\hline John & & & 5.5 \\
$\quad$ Baseline & 22 & 4 & 20.4 \\
$\quad$ Postintervention & 143 & 7 & 0.8 \\
David & 5 & 6 & 12.4 \\
$\quad$ Baseline & 136 & 11 & 4.1 \\
$\quad$ Postintervention & 33 & 8 & 4.6 \\
George & 23 & 5 & 17.0 \\
$\quad$ Baseline & 153 & 9 & \\
$\quad$ Intervention Group 1 & & & \\
$\quad$ Intervention Group 2 &
\end{tabular}

Note: Each session includes combined data for both lunchtime and recess.

intervention. David showed an increase from 0.04 responses per minute in baseline to 0.60 per minute following intervention. George averaged 0.13 responses per minute in baseline, 0.07 responses per minute during the first phase of intervention (with Group 1 of trained peers), and 0.42 responses per minute in the second phase of intervention (with Group 2 of trained peers).

\section{Initiations by Students With ASD Toward Peers}

The rate of initiations made by students with ASD toward their peers is also presented in Figure 2. Because the students with ASD were not aware that any of their peers had received training, it was not expected that the students with ASD would initiate interactions preferentially with either trained or untrained peers. Therefore observers did not record initiation data for trained and untrained peers separately. As shown, the mean rate of initiations increased for two of the three participants following the peer training intervention. John showed similar rates in baseline and postintervention phases, with 0.28 initiations per minute during baseline and 0.33 per minute following intervention. David showed an increase from an average of 0.01 initiations per minute in baseline to an average of 0.43 per minute following intervention. For George, data reflected a low level of initiations, 0.07 per minute, during baseline. In the first phase of intervention (Group 1), initiations remained relatively stable at 0.05 per minute, but in the second phase (Group 2), there was an increase in initiations to an average of 0.29 per minute.

\section{Peer Responses to Initiations Made by Students With ASD}

Figure 3 shows data for peer responses to initiations made by the students with ASD. Peer responses include data for both trained and untrained peers combined. John's peers averaged 0.08 responses per minute in baseline and 0.23 per minute following intervention. David's peers averaged 0.01 responses per minute in baseline and 0.53 per minute following intervention. George's peers averaged 0.04 responses per minute in baseline, 0.04 per minute in the first phase of intervention, and 0.20 responses per minute during the second phase.

\section{Discussion}

Consistent with previous research on peer training, the current study demonstrates that peer training can be a viable strategy for increasing interactions between typical peers and students with ASD (Kamps et al., 2002; Kohler et al., 1995; Lee \& Odom, 1996; Strain, 1983). Importantly, this investigation focused on social behaviors that took place in natural social contexts in public schools-specifically, lunchtime and recess-thereby addressing ecological validity issues relevant to typical school settings. While the generalizability of the current findings is subject to the limitations of a study design involving only three participants, the results provide further evidence for the effectiveness of peer-mediated interventions in building social interactions between students with ASD and their classmates. 
Figure 2

Initiations and Responses per Minute by the Students With Autism Spectrum Disorders

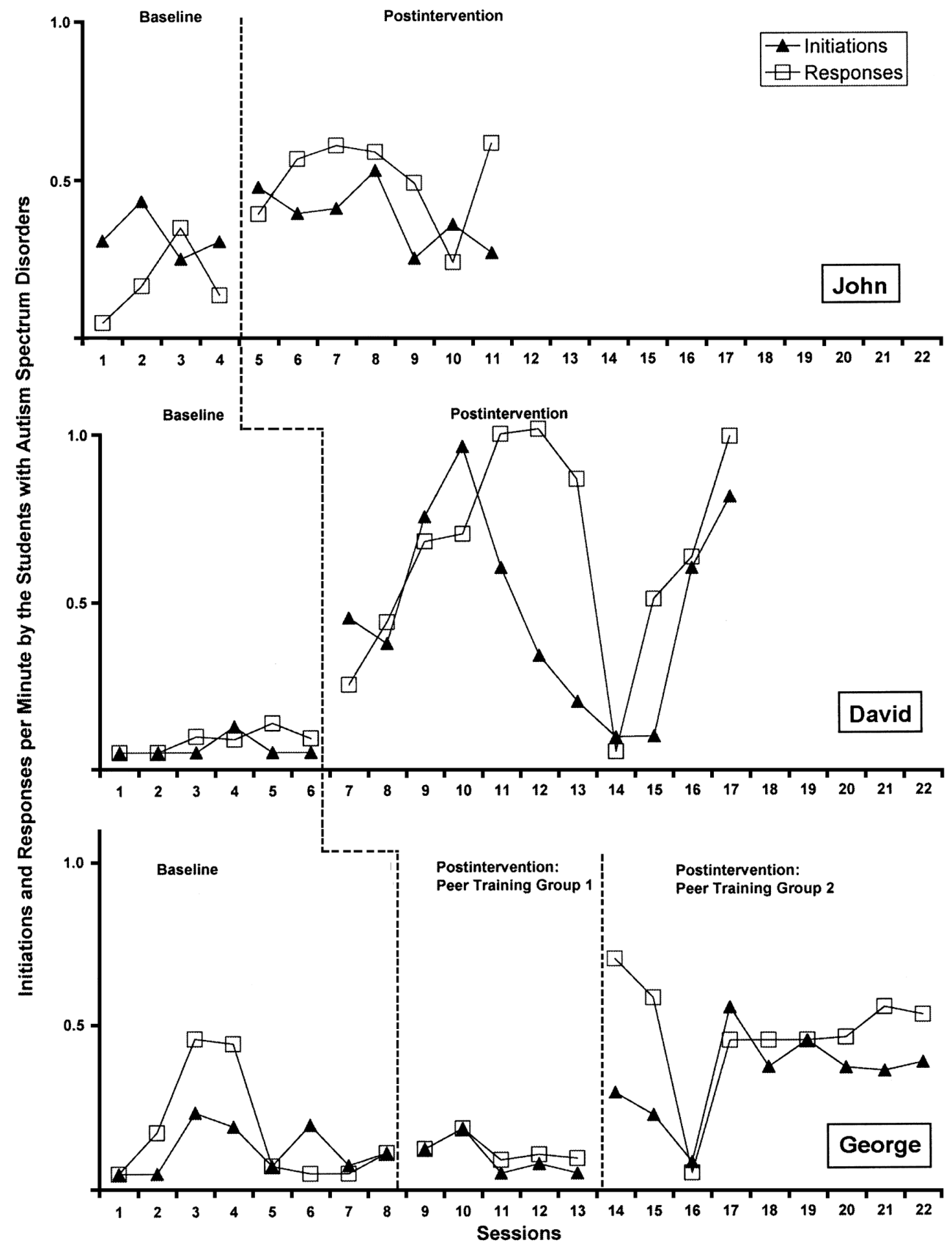

Although the peer training intervention was generally successful for each participant, as evidenced in Figure 1, trained and untrained peers exhibited very low initiations during at least one observation session in the postintervention phase. The authors can only speculate about the causes for these results. For two of the participants, David and George, anecdotal and observational reports indicated that the participants were sick during these low points (allergies and a cold, respectively). Perhaps this variability should be viewed in light of the fact that that the valence of social reinforcers may be highly affected by contextual variables such as setting events (mood, fatigue, illness, etc.; Carr, Magito McLaughlin, Giacobbe-Grieco, \& Smith, 2003; Carr \& Owen-DeSchryver, 2007). Although these events were not addressed in the present study, it is possible that all children experience events that make them more or less motivated to engage in social interactions on any given day. When experiencing a negative setting event, 
Figure 3

Peer Responses per Minute to Social Initiations Made by the Students With Autism Spectrum Disorders

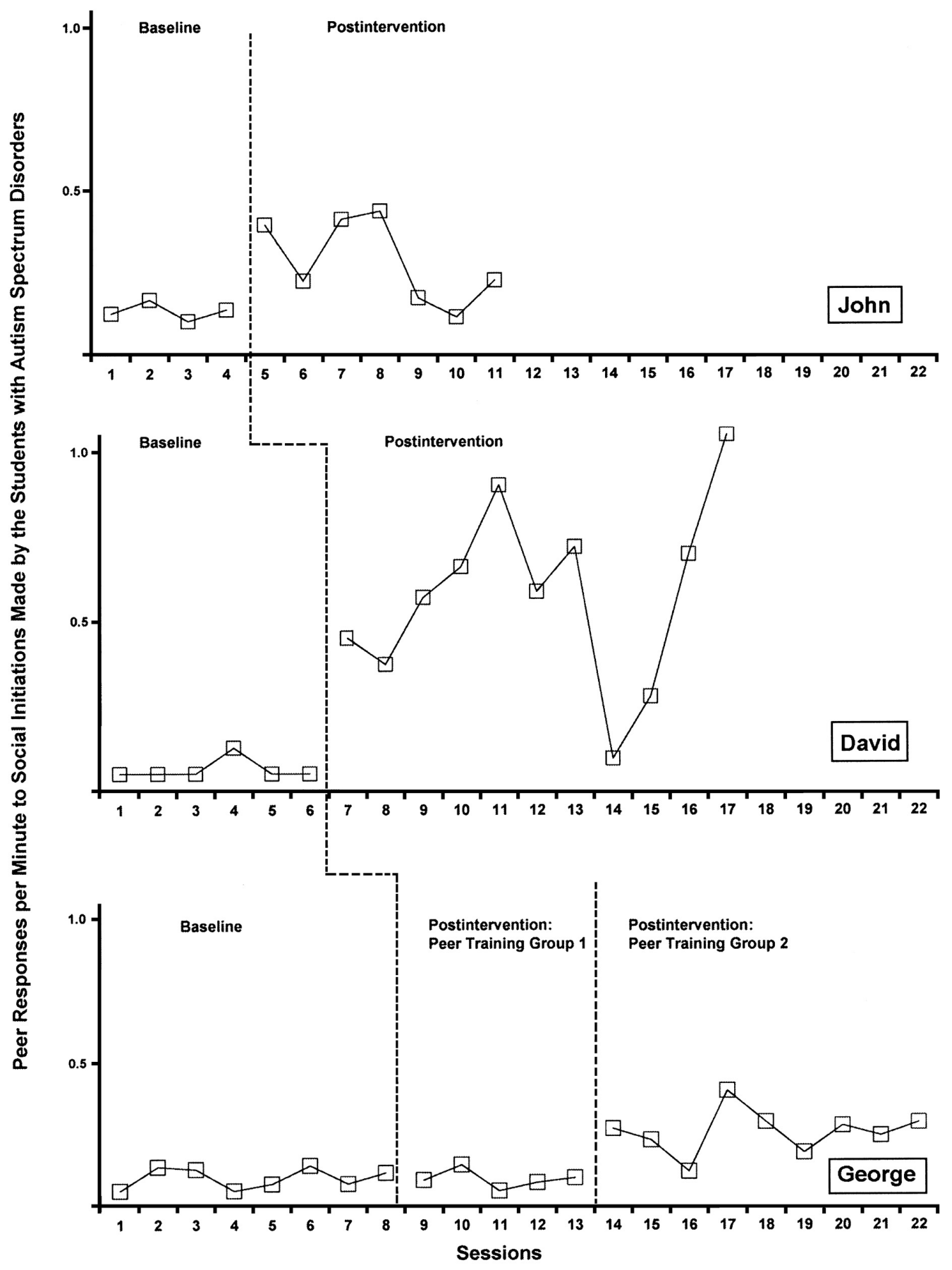

students with ASD may be more likely to rebuff their peers, leading the peers to reduce their initiations temporarily.

As is also depicted in Figure 1, Group 1 of trained peers for George did not show increased initiations following training. Researchers have not yet determined why some peer training interventions are successful while others are not, but the present study points to some potential variables meriting further investigation. Only two out of three peers originally targeted participated in the initial training group for George. The fact that George's Group 1 was smaller than the other training groups may have interfered with the success of peer training for one or both of two possible reasons. First, previous research has suggested that generalization of 
social behaviors between typical peers and students with ASD may improve when multiple peers are trained (Pierce \& Schreibman, 1997). While there are many potential reasons for this, one possibility is that when multiple peers are trained, the peers may provide supportive prompts to one another during interactions with students with special needs (Kohler et al., 1995). Second, in the present investigation the training involved a discussion-oriented, guided exchange of ideas between peers and facilitators, a format that may have been less effective when fewer peers were involved.

The current investigation also illustrates the potential mediating role of peer gender in the success of peer training interventions. Whereas the peer groups for the other participants consisted of mixed gender groupings, the initial group of peers selected for training with George involved only boys, based on both teacher recommendation and classroom observations where George appeared to demonstrate a strong interest in playing with his classmates who were boys. The data from the study indicate a substantial increase in peer initiations immediately following the training of the three girls who made up Group 2 of peer training. This is consistent with previous research summarized by Center and Curry (1993) suggesting that at elementary ages, girls are "more responsive" to students with special needs (p. 233), and is also supported by anecdotal observations of students in inclusive settings that indicate that girls, particularly at young ages, tend to be more nurturing and mature than boys and thus may respond better to this type of training. Additional research on other peer characteristics, such as popularity, might also be useful guides for professionals selecting peers to participate in training. Garrison-Harrell and Kamps (1997) selected peers for a peer networking intervention based on the social status of the peers (i.e., their popularity), but to date there is very little substantive research on the peer characteristics associated with successful implementation of such interventions.

Perhaps the most unexpected and central finding of the present study is that initiations toward the students with ASD increased for untrained-as well as for trained-peers following intervention. These untrained peers included other students involved in lunchtime and recess activities who were all in the same grade as the students with ASD but not necessarily from the same classroom. Changes in peer initiations were clearly linked with the intervention phase for all three participants, except for Group 1 of George's peers. For George, it was not until trained peer initiations increased after Group 2 was trained that there was a concomitant increase in initiations by untrained peers. This finding may suggest that the underlying mechanism associated with the increase in untrained peer initiations was the changing behavior of the trained peers rather than other variables such as the presence of the researchers.

While the specific variables accounting for the significant increase in initiations by untrained peers were not directly explored in the present investigation, there are several possible explanations. The effect might be explained in terms of modeling (Bandura, 1969; Elliott \& Vasta, 1970; Hartup \& Coates, 1967), whereby untrained peers observed and modeled the behavior of trained peers who engaged in interactions with students with ASD. Consequently, they may have been exposed to naturally occurring reinforcers from either the trained peers (e.g., attention or increased positive interactions) or the students with ASD (e.g., positive verbalizations or affective responses, such as smiling or laughing) as they participated in interactions with the students with ASD. While it is also possible that untrained peers may have increased their interactions with students with ASD in an attempt to gain reinforcement from adults, it is unlikely that this robust change was due merely to the presence of the researchers. Researchers were trained to maintain standard responses in baseline and intervention, and in neither condition did they provide verbal praise or other reinforcement to peers for their participation in interactions with the students with ASD.

Another interesting implication of the present study is that it may not always be necessary to devote significant instructional resources to social skills instruction for students with ASD if peers are adequately trained. As shown in Figure 2, although the students with ASD were not directly targeted by the intervention and did not participate in training to facilitate interactions, they often demonstrated more initiations to their peers in the postintervention phase. This finding is similar to that described by McGee et al. (1992), who found that one of three participants showed increased initiations after intervention was implemented even though the intervention targeted only peers. It is not clear why both David and George showed increased initiations in the absence of specific training. However, it is likely that as they became engaged in mutually reinforcing activities with their peers they were also exposed to cues or features of those activities that evoked social behaviors (e.g., asking a peer "Who's it?" during a game of tag). The failure of John's initiations to increase during the intervention phase may be because his baseline level of initiations was already within the range established during intervention for David and George. Pollard (1998) suggests that it is important to assess changes in the social behaviors of children with ASD in comparison with typical 
social behavior as a means of determining whether observed improvements are approaching the norm. While there is limited research on this topic for children with ASD, a study by McGrath et al. (2003) showed that typical preschoolers averaged 0.50 initiations per minute during a 10-min session. In the present study, John initiated an average of 0.28 times per minute in baseline. This is significantly higher than baseline levels for both David and George, and these data suggest that John's baseline level of initiations was approaching the typical level noted by McGrath et al. (It should be noted, however, that McGrath et al.'s data refer to initiations made by preschool children, and it is unclear whether the rates would be similar for typical second-grade or fourthgrade students.) Future research might assess the frequency of initiations made by students at different ages, as well as by both shy and extraverted students. This information could then be used to help establish an ideal target range of initiations for students with ASD.

In the present study, both the peers and the students with ASD showed an increase in the rate of responses during intervention (see Figures 2 and 3). It is possible that the peer training was partly responsible for the improvement in responses by peers, as peers were provided with information that may have helped them to respond more effectively during their interactions with classmates with ASD. It is also possible that the increased frequency of initiations by the students with ASD created a larger number of opportunities for peers to respond, leading directly to a larger number of responses. This is the case for both the students with ASD and the peers, as the frequency of opportunities to respond increased for both groups following intervention. These results further illustrate the fluid, and necessarily reciprocal, nature of social interactions, indicating that interventions targeting one component (social initiations by peers) may have simultaneous effects on another component (initiations by students with ASD) and, potentially, reciprocal effects on yet another component (responses by peers). One benefit of this reciprocity is that each initiation by a peer allows the student with ASD an opportunity to practice a response. DiSalvo and Oswald (2002) indicated that a major goal of peer training is to teach peers to initiate social interactions with students with ASD more frequently so that the students with ASD can be involved in more interactions, each of which provides an opportunity for reinforcement for appropriate social responding. One can therefore speculate that as students with ASD become the recipients of more frequent initiations from peers, they are likely to become better, more efficient, and more appropriate responders because they will have the opportunity to practice and perform social skills repeatedly, rather than just performing them on a few sporadic occasions.

There are, however, several important issues not addressed in the present investigation. It is unclear whether the intervention was successful in making longterm changes in the social environment, as no follow-up data were collected. Additionally, the study did not address whether the intervention was associated with changes in qualitative aspects of the social interactions between students with ASD and their peers. It is possible that the peer training intervention increased the frequency of interactions and allowed students greater opportunities to respond to their peers but did not affect social relationships in a meaningful way. Future studies might better address qualitative changes in social interactions by using a data collection system that allows measurement of changes in the duration of interactions or in subtle aspects of student behavior, such as the level of engagement or affect of students with ASD. Indeed, Lord (1995) suggested that affect may be a more salient domain for study than social initiations in determining the effectiveness of peer-mediated interventions for students with ASD. Future studies on peer-mediated interventions would also benefit from incorporating social validity data. Such data could be collected from parent, teacher, lunch or recess aide, peer, or participant reports of changes in social relationships and opportunities that might be direct or indirect results of the intervention. For instance, data might be collected on the participation of the student with ASD in extracurricular activities, parties, and other social events with classmates. While formal social validity data were not collected in the present study, anecdotal reports suggested that the intervention was not disruptive to classroom activities and was valued by most parents, teachers, and peers who were involved.

In sum, the present investigation replicated and extended previous research demonstrating that peermediated interventions can successfully increase interactions between students with ASD and their peers. More important, it showed that increasing initiations between students with ASD and their peers by training a small number of peers may also have positive effects on interactions with untrained peers as well. This finding may have important practical implications in the present educational climate. The pressures of the current system are such that there is little classroom time available to devote to social skills instruction, particularly in grade levels focusing heavily on academic outcomes. If the social opportunities between students with ASD and a broad base of peers can be increased through strategies that target only a few peers, professionals will be providing 
students with ASD with a great service while ensuring that critical instructional time is not being diverted from the academic curriculum for the majority of students. Future research on peer-mediated interventions should address complex, critical variables such as peer and student characteristics associated with successful peer training, as well as qualitative changes in social interactions between students with ASD and their peers, to ensure that the outcomes of peer-mediated interventions legitimately induce long-term, socially valid changes in social relationships and opportunities.

\section{References}

American Psychiatric Association. (2000). Diagnostic and statistical manual of mental disorders (4th ed., text rev.). Washington, DC: Author.

Anderson, A., Moore, D. W., Godfrey, R., \& Fletcher-Flinn, C. M. (2004). Social skills assessment of children with autism in freeplay situations. Autism, 8, 369-385.

Bandura, A. (1969). Principles of behavior modification. New York: Holt, Rinehart \& Winston.

Carr, E. G., Magito McLaughlin, D., Giacobbe-Grieco, T., \& Smith, C. E. (2003). Using mood ratings and mood induction in assessment and intervention for severe problem behavior. American Journal on Mental Retardation, 108, 32-55.

Carr, E. G., \& Owen-DeSchryver, J. S. (2007). Physical illness, pain, and problem behavior in minimally verbal people with developmental disabilities. Journal of Autism and Developmental Disorders, 37, 413-424.

Center, Y., \& Curry, C. (1993). A feasibility study of a full integration model developed for a group of students classified as mildly intellectually disabled. International Journal of Disability Development and Education, 40, 217-235.

Davis, M., Langone, J., \& Malone, D. M. (1996). Promoting prosocial behaviours among preschool children with and without disabilities. International Journal of Disability Development and Education, 43, 219-246.

Dawson, G., Toth, K., Abbott, R., Osterling, J., Munson, J., \& Estes, A. (2004). Early social attention impairments in autism: Social orienting, joint attention, and attention to distress. Developmental Psychology, 40, 271-283.

DiSalvo, C. A., \& Oswald, D. P. (2002). Peer-mediated interventions to increase the social interaction of children with autism: Considerations of peer expectancies. Focus on Autism and Other Developmental Disabilities, 17, 198-207.

Elliott, R., \& Vasta, R. (1970). The modeling of sharing: Effects associated with vicarious reinforcement, symbolization, age, and generalization. Journal of Experimental Child Psychology, 10, 8-15.

Fritz, M. F. (1990). A comparison of social interactions using a friendship awareness activity. Education and Training of the Mentally Retarded, 25, 352-359.

Garrison-Harrell, L., \& Kamps, D. (1997). The effects of peer networks on social-communicative behaviors for students with autism. Focus on Autism and Other Developmental Disabilities, 12, 241-255.

Gonzalez-Lopez, A., \& Kamps, D. M. (1997). Social skills training to increase social interactions between children with autism and their typical peers. Focus on Autism and Other Developmental Disabilities, 12, 2-14.
Handleman, J. (1999). Assessment for curriculum planning. In D. Berkell-Zager (Ed.), Autism: Identification, education \& treatment (2nd ed., pp. 99-110). Mahwah, NJ: Lawrence Erlbaum.

Harrower, J. K., \& Dunlap, G. (2001). Including children with autism in general education classrooms. Behavior Modification, 25, 762-784.

Hartup, W. W., \& Coates, B. (1967). Imitation of a peer as a function of reinforcement from the peer group and rewardingness of the model. Child Development, 38, 1003-1016.

Hilton, A., \& Liberty, K. (1992). The challenge of ensuring educational gains for students with severe disabilities who are placed in more integrated settings. Education and Training of the Mentally Retarded, 27, 167-175.

Individuals with Disabilities Education Improvement Act of 2004, 20 U.S.C. $§ 1400$ et seq. (2004) (reauthorization of the Individuals with Disabilities Education Act of 1990)

Kamps, D., Gonzalez-Lopez, A., Potucek, J., Kravits, T., Kemmerer, K., \& Garrison-Harrell, L. (1998). What do the peers think? Social validity of integrated programs. Education \& Treatment of Children, 21, 107-134.

Kamps, D., Potucek, J., Lopez, A., Kravits, T., \& Kemmerer, K. (1997). The use of peer networks across multiple settings to improve social interaction for students with autism. Journal of Behavioral Education, 7, 335-357.

Kamps, D., Royer, J., Dugan, E., Kravits, T., Gonzalez-Lopez, A., Garcia, J., et al. (2002). Peer training to facilitate social interaction for elementary students with autism and their peers. Exceptional Children, 68, 173-187.

Kanner, L. (1943). Autistic disturbances of affective contact. Nervous Child, 2, 217-250.

Kazdin, A. E. (1982). Single-case research designs. New York: Oxford University Press.

Kohler, F. W., Strain, P. S., Hoyson, M., Davis, L., Donina, W. M., \& Rapp, N. (1995). Using a group-oriented contingency to increase social interactions between children with autism and their peers: A preliminary analysis of corollary supportive behaviors. Behavior Modification, 19, 10-32.

Laushey, K., \& Heflin, L. J. (2000). Enhancing social skills of kindergarten children with autism through the training of multiple peers as tutors. Journal of Autism and Developmental Disorders, 30, 183-193.

Lee, S., \& Odom, S. L. (1996). The relationship between stereotypic behavior and social interaction for children with severe disabilities. The Journal of the Association for Persons with Severe Handicaps, $21,88-95$.

Lord, C. (1995). Facilitating social inclusion: Examples from peer intervention programs. In E. Schopler \& G. Mesibov (Eds.), Learning and cognition in autism (pp. 221-240). New York: Plenum.

McEvoy, M. A., Shores, R. E., Wehby, J. H., Johnson, S. M., \& Fox, J. J. (1990). Special education teachers' implementation of procedures to promote social interaction among children in integrated settings. Education and Training of the Mentally Retarded, 25, 267-275.

McGee, G. G., Almeida, M. C., Sulzer-Azaroff, B., \& Feldman, R. S. (1992). Promoting reciprocal interactions via peer incidental teaching. Journal of Applied Behavior Analysis, 25, 117-126.

McGrath, A., Bosch, S., Sullivan, C., \& Fuqua, R. W. (2003). Training reciprocal social interactions between preschoolers and a child with autism. Journal of Positive Behavior Interventions, 5, 47-54.

Morrison, L., Kamps, D., Garcia, J., \& Parker, D. (2001). Peer mediation and monitoring strategies to improve initiations and social skills for students with autism. Journal of Positive Behavior Interventions, 3, 237-250. 
Nabors, L., Willoughby, J., Leff, S., \& McMenamin, S. (2001). Promoting inclusion for young children with special needs on playgrounds. Journal of Developmental and Physical Disabilities, 13, 179-190.

National Research Council, Division of Behavioral and Social Sciences and Education, Committee on Educational Interventions for Children with Autism. (2001). Educating children with autism. Washington, DC: National Academy Press.

Owen-DeSchryver, J. (2002). The boy in my class. Unpublished manuscript, Grand Valley State University, Allendale, MI.

Pierce, K., \& Schreibman, L. (1997). Multiple peer use of pivotal response training to increase social behaviors of classmates with autism: Results from trained and untrained peers. Journal of Applied Behavior Analysis, 30, 157-160.

Pollard, N. L. (1998). Development of social interaction skills in preschool children with autism: A review of the literature. Child \& Family Behavior Therapy, 20, 1-16.

Rogers, S. J. (2000). Interventions that facilitate socialization in children with autism. Journal of Autism and Developmental Disorders, 30, 399-409.

Strain, P. S. (1983). Generalization of autistic children's social behavior change: Effects of developmentally integrated and segregated settings. Analysis and Intervention in Developmental Disabilities, 3, 23-34.

Tawney, J. W., \& Gast, D. L. (1984). Single-subject research in special education. Columbus, OH: Merrill.

Wechsler, D. (1991). Wechsler Intelligence Scale for Children (3rd ed.). San Antonio, TX: Psychological Corp.

Jamie S. Owen-DeSchryver, $\mathrm{PhD}$, is an assistant professor of psychology at Grand Valley State University in Allendale,
Michigan. Her current research interests include evaluation of school-based intervention strategies for preschoolers with autism spectrum disorders (ASD) and strategies to improve professional development for public school personnel serving students with ASD. Please address correspondence to Jamie OwenDeSchryver, Grand Valley State University, 2195 Au Sable Hall, Allendale, MI 49401; e-mail: owendesj@gvsu.edu

Edward G. Carr, $\mathrm{PhD}$, is leading professor in the Department of Psychology at the State University of New York at Stony Brook. His research interests include autism, community integration, family support, systems change, biomedical factors, and problem behavior.

Sanja I. Cale, $\mathrm{PhD}$, is an assistant professor of education at Long Island University and an educational consultant with the Institute for Children with Autism in Riverhead, New York. Her current research interests include the implementation of peer support strategies for elementary and middle school students with ASD.

Audrey Blakeley-Smith, $\mathrm{PhD}$, is an assistant professor in the Department of Psychiatry at the University of Colorado at Denver Health Sciences Center. Her current research interests include school-based interventions and anxiety treatment for children with ASD. 